\title{
4
}

\section{Challenging Problems in the Surgical Management of Melanoma}

\author{
Asvin M. Ganapathi, Douglas S. Tyler and Paul J. Mosca \\ Department of Surgery, Duke University Medical Center
}

Durham, NC 27710

USA

\section{Introduction}

The surgical management of cutaneous melanoma can occasionally present serious challenges even to experienced surgeons. Management problems range from selecting the best surgical intervention at the time of initial diagnosis of a primary tumor to establishing whether surgery has a role in palliation of advanced disease. We will review the relevant literature and discuss recommended approaches to management in order to address several areas of debate or uncertainty in the surgical management of melanoma.

\section{Surgical management of melanocytic lesions of uncertain malignant potential}

The diagnosis of melanoma should be considered in the evaluation of all melanocytic skin lesions and all skin lesions with aggressive clinical behavior. Melanocytic lesions raising a suspicion of melanoma may be referred to using a variety of terms, such as "atypical Spitz nevus", "atypical melanocytic proliferation", "melanocytic tumor of uncertain malignant potential" ("MELTUMP"), "cellular blue nevus", and others. When referred a patient with such a lesion, it is critically important that the treating surgeon thoroughly review available histopathologic descriptions regarding the lesion, have outside slides reviewed by a qualified dermatopathologist, communicate with the pathologist to ensure that all information necessary to guide treatment is provided, and obtain outside dermatopathology consultation if indicated. Most importantly, the clinician must recognize that proper management of melanocytic lesions of uncertain malignant potential depends not only on the pathology report per se, but also on the clinical context of the lesion.

While melanoma is often a relatively straightforward diagnosis, there are many cases in which it is difficult or impossible to differentiate between melanoma and lesions of benign or uncertain biologic behavior [Barnhill et al., 1999; Scolyer et al., 2004]. One of the lesions that may be among the most difficult to differentiate from melanoma is the atypical Spitz tumor. This diagnosis not only carries important prognostic information for the patient, but also may be associated with significant anguish and can be a source of medicolegal liability if improperly managed. Consequently, it is important to convey the nature of uncertainty regarding the diagnosis, and when appropriate, advocate an aggressive approach to management. 
One method that has been advocated as a strategy for differentiating between melanomas and similar lesions is the sentinel lymph node biopsy. The literature has shown that in cases of lesions with unknown malignant potential there is a $16-47 \%$ positive SLNB rate [Berk et al., 2010; Ghazi et al., 2010; Ludgate et al., 2009; Magro et al., 2010; Meyers et al., 2010]. Interestingly, atypical spitzoid lesions appear to have a high incidence of microscopic nodal involvement, but a more favorable prognosis than common melanomas [Ludgate et al, 2009]. In a study of 31 patients undergoing SLNB for atypical melanocytic neoplasms, younger median age (11 versus 23.5$)$ and greater thickness $(1.90 \mathrm{~mm}$ versus $1.09 \mathrm{~mm})$ were associated with a nodal metastasis [Meyers et al, 2010]. Thus, a negative SLNB does not prove that a lesion is benign but does provide reassurance that it is localized. A positive SLNB result, on the other hand, is more valuable with respect to establishing the diagnosis, and it confirms the presence of regional nodal disease. Performance of SLNB should be considered in the management of atypical melanocytic neoplasms, particularly in a younger patient or a patient with a thicker lesion.

New and emerging technologies may provide additional tools to help differentiate these lesions from melanoma. One such technology is comparative genomic hybridization. It has been reported that approximately $95 \%$ of melanomas have chromosomal abnormalities [Scolyer et al., 2010], while melanocytic nevi rarely have such chromosomal aberrations [Bastian et al., 2000; Bastian et al., 2003; Carless \& Griffiths, 2008; Casorzo et al., 2005; Pirker et al., 2003; Stark \& Hayward, 2007]. One drawback to this technique is the availability and cost of this technology. Another method that may be helpful in distinguishing between nevi and melanoma is fluorescence in-situ hybridization (FISH) [Gerami et al., 2009; Morey et al., 2009; Newman et al., 2009; Pouryazdanparast et al., 2009]. Finally, it has also been shown that BRAF and NRAS mutations are commonly seen in melanomas but not in Spitz nevi, while HRAS mutations sometimes occur in Spitz nevi, but are not usually seen in melanomas [Scolyer et al, 2010].

Despite the availability of these sophisticated analyses, some lesions will remain difficult or impossible to definitively classify. In these cases, discussion in the context of a multidisciplinary melanoma/pigmented lesion clinic or conference is recommended. In cases in which a consensus is unable to be reached regarding the diagnosis, then appropriate wide excision, if possible, should be performed in order to treat, according to the "worstcase scenario". At times, melanoma may be confirmed upon re-excision, in which case it is reasonable to consider proceeding with SLNB if not already performed. As routine use of imaging or laboratory tests for staging is not recommended for localized, early stage primary melanomas, such extensive staging evaluation is rarely indicated prior to surgery for pigmented lesions of uncertain biologic potential. Certainly, if advanced melanoma is confirmed or strongly suspected, then appropriate staging is indicated. Finally, the foundation for management of diagnostically challenging pigmented skin lesions is effective two-way communication and careful attention to the patient's level of understanding, wishes, and expectations regarding management.

\section{Indication for and appropriateness of sentinel lymph node biopsy}

\subsection{SLNB for thin and thick melanomas}

While the value of sentinel lymphadenectomy in the nodal staging of malignant melanoma has been well documented in the literature, there remain questions regarding optimal application of the technique [Bagaria et al., 2010; Essner, 2010; Phan et al., 2009; van Akkooi 
et al., 2009]. In general, for a clinically node negative patient with a primary lesion that is thicker than $1 \mathrm{~mm}$ - particularly in the $1-4 \mathrm{~mm}$ range - consideration should be given to performing a sentinel lymph node biopsy (SLNB) [Garbe et al., 2010; Testori et al., 2009]. The value of SLNB in patients with melanomas less than $1 \mathrm{~mm}$ (T1; "thin") or greater than $4 \mathrm{~mm}$ (T4; "thick") in thickness remains less well defined.

Patients with primary tumors less than $1 \mathrm{~mm}$ in thickness generally do not have a high enough probability of harboring nodal micrometastasis to warrant SLNB for nodal staging. However, the need for SLNB is often considered in these T1 tumors, and it has even been suggested that this threshold should lowered to $0.75 \mathrm{~mm}$ [Wong et al., 2006b]. For tumors less than $1 \mathrm{~mm}$ in thickness, it is appropriate to factor in other clinical and histopathologic factors. Although it is tempting to recommend SLNB for all melanomas above $0.75 \mathrm{~mm}$ in thickness or less than $1 \mathrm{~mm}$ in thickness with adverse prognostic histopathologic features, this approach may be an overly liberal application of the technique. In fact, a number of studies have documented a very low incidence of positive SLNB in patients with T1 lesions, generally 5\% or less [Berk et al., 2005; Cecchi et al., 2007; Karakousis et al., 2006; Kesmodel et al., 2005; Wong et al., 2006a]. In a Memorial Sloan Kettering study of patients with T1 melanomas undergoing SLNB, 8 (3.2\%) of 223 patients had positive nodes [Wong et al, 2006a]. Interestingly, all those patients with positive nodes had melanomas between .75 and $1 \mathrm{~mm}$ in thickness and had a Clark level of IV (i.e., Breslow thickness-Clark level discordance). In this study, ulceration was not predictive of a positive SLN, but in several other studies, ulceration was found to be associated with regional nodal metastasis in patients with T1 melanomas undergoing SLNB [Karakousis et al, 2006; Sondak et al., 2004; Wagner et al., 2000]. It has become clear that mitotic activity is a significant histopathologic prognostic factor for survival in melanoma, and it has replaced Clark level in the $7^{\text {th }}$ version of the AJCC staging system, upstaging the primary tumor from T1a to T1b [Balch et al., 2009]. Mitotic activity has also been shown to be predictive of nodal micrometastasis. A Michigan study found that not only does mitotic activity increase the probability of nodal metastasis in the setting of T1 primary tumors, but the relative impact of mitotic activity increases progressively with the number of mitoses observed [Paek et al., 2007]. Interestingly, the relationship between mitotic activity and nodal metastasis is most pronounced in younger patients, and this relationship diminishes markedly with advanced age. Younger age itself, angiolymphatic invasion, and trunk or lower extremity primary tumor have also been associated with a positive SLNB [Paek et al, 2007; Sondak et al, 2004]. Regression, however, has not been found to be a predictor of SLN metastasis [Cecchi et al., 2008; Socrier et al., 2010].

It is important to consider that sentinel lymphadenectomy is not without risk and adds significant expense to the care of melanoma patients. Potential complications include seroma, hematoma, usually transient and/or minor nerve palsies, lymphedema, and rarely anaphylaxis associated with isosulfan blue [Lucci et al., 2007; Roaten et al., 2005]. The overall complication rate of SLNB alone in the Sunbelt Melanoma Trial, which enrolled over 2100 patients, was $4.6 \%$ [Wrightson et al., 2003]. Given the overall low incidence of positive SLNB in patients with T1 lesions, it is inappropriate to perform SLNB routinely in this group of patients. Patients with thicker T1 lesions associated with histopathologic factors that increase the probability of nodal micrometastasis should prompt consideration of nodal staging, particularly in patients with a long life expectancy. In these appropriately selected patients with $\mathrm{T} 1$, clinically node negative primary tumors, a balanced discussion regarding the potential value, as well as the risks, of performing a sentinel lymph node biopsy is recommended. 
A final issue regards nodal staging in patients who are clinically node-negative but have T4 (> $4 \mathrm{~mm}$; "thick") primary tumors. It may be argued that there is little value associated with SLNB in patients with thick melanomas since there is a high rate of systemic and/or regional disease at the time of diagnosis, and that the prognostic utility of SLNB is lower in these patients [Perrott et al., 2003]. Other studies reinforced this belief by demonstrating no significant difference in overall survival in patients who undergo SLNB for thick melanomas relative to those who do not [Cherpelis et al., 2001; Essner et al., 2002; Jacobs et al., 2004]. However, a study done by Gajdos et al. demonstrated that patients with T4 tumors with a negative SLNB experienced a longer disease-free and overall survival than those with a positive SLNB [Gajdos et al., 2009]. In fact, some patients with T4 disease may be candidates for adjuvant therapy, and the status of the SLN may impact the decision regarding adjuvant treatment [Gajdos et al, 2009]. It has also been recommended that SLNB be performed for thick melanomas because of its strong independent prognostic value [Carlson et al., 2003; Ferrone et al., 2002; Gershenwald et al., 2000].

Thus, it appears that SLNB should be considered as an option in selected patients with T4 primary tumors. Certainly, the most elderly of patients and/or those patients with major medical comorbidities with a poor performance status would not typically be offered SLNB in this setting. In otherwise healthy candidates, SLNB may be especially helpful in patients with non-ulcerated primary tumors or patients in whom nodal staging is expected to impact management, including administration of adjuvant therapy.

\subsection{SLNB for head and neck melanomas}

Another group of patients for whom the value of performing a SLNB may be uncertain is that with head and neck primary tumors, and this topic has recently been reviewed in depth [De Rosa et al., 2011]. Since the frequency of positive SLNs is in the 7-26\% range, SLNB may be a valuable staging tool for patients with head and neck melanomas [Alex et al., 1998; Carlson et al., 2000; Jansen et al., 2000; O'Brien et al., 1995; Rasgon, 2001; Wells et al., 1997]. One of the greatest concerns about performing SLNB for lesions in the head and neck is injury, particularly to nerve structures such as the facial nerve [Eicher et al., 2002]. Another concern is that the drainage pattern of the lymphatics of the head and neck is considerably more complex than those in other regions of the body. Detailed mapping of head and neck lymphatics has shown unexpected drainage patterns in 8-43\% of patients. [Klop et al., 2011; O'Brien et al, 1995]. A study by Kelly et al. showed that, while the procedure was safe, there was a false negative rate of $9.5 \%$ and a failure to locate a lymph node in $32.5 \%$ of patients [Kelly et al., 2009]. This high failure rate was attributed to complex drainage patterns as well as surgeon experience.

Some surgeons have taken a liberal approach to application of SLNB in head and neck melanomas. Some recommend that SNLB be performed in all patients with head and neck tumors thicker than $0.75 \mathrm{~mm}$ [Patel et al., 2002], and indeed some studies have shown superior results. Gomez-Rivera and colleagues reported a success rate of SLNB in head and neck melanomas of 96\% [Gomez-Rivera et al., 2008]. In another series of 106 patients, SLNs were identified in $89 \%$ of patients [Teltzrow et al., 2007]. The median follow-up was 47 months, and 8 additional patients developed recurrence within the regional nodes, which translated into a sensitivity of $68 \%$. In another study, SLNs were identified in 41 of 44 patients $(94 \%)$ and there were no regional nodal recurrences, but this study was limited by a short median follow-up of 22.4 months [MacNeill et al., 2005]. A large retrospective study of over a thousand patients who underwent SLNB for melanoma was performed, and head 
and neck location was associated with a higher false-negative SLN rate compared to primary tumors in other locations [Carlson et al., 2008].

Based on the literature, SLNB for head and neck melanomas is safe in the hands of experienced surgeon and when appropriate pre-operative planning is done. However, the risks should be fully discussed with the patient before proceeding with SLNB. In this region, there are more complex lymphatic drainage patterns involving multiple lymph node basins, and the success of identifying SLNs may be lower than in other regions, particularly when the surgeon has less experience with head and neck SLNB. It has been proposed that the higher-resolution, three-dimensional images achieved with SPECT/CT imaging may enhance detection of SLNs and decrease risks by limiting the dissection necessary for SLNB [Even-Sapir et al., 2003; Roarke et al., 2007; Vermeeren et al., 2010], but this remains to be determined. Patients should be informed that an attempted SLNB may be unsuccessful, in which case the risks, cost, and discomfort associated with the procedure are incurred without added benefit to wide excision alone. Nevertheless, sentinel lymphadenectomy is a reasonable, though not mandatory procedure and may provide valuable staging information as part of the surgical management of patients with head and neck melanomas.

\subsection{Complex drainage patters or failure to localize sentinel lymph nodes by lymphoscintigraphy}

In the previous section, the possibility that the surgeon may fail to identify SLNs was discussed. A specific manifestation of this problem that occasionally arises is the failure of radiocolloid lymphoscintigraphy to locate any SLNs whatsoever. A related problem regards the approach to sentinel lymph node biopsy when mapping has shown a complex drainage pattern, such as a diffuse chain of lymph nodes extending from the inguinofemoral nodal basin up into the pelvic nodal basin. There is little literature guiding management in these circumstances.

The first step in preparing for unexpected results or complexities of lymphoscintigraphy is planning, and this starts with properly informing patients about the potential implications of lymphoscintigraphy and the decision making process that might be anticipated as a consequence. The next critical element is good communication and a close collaborative relationship with the nuclear medicine staff. Third, there should be some thought about contingency plans prior to the procedure, and these may be individualized depending on the particular patient, anatomic considerations, and lymphoscintigraphy results.

Perhaps among the most common questions is how to manage a situation in which lymphoscintigraphy fails to localize any sentinel lymph nodes whatsoever. This problem may make it impossible to determine the draining nodal basins and therefore may lead to a lower rate of complete and accurate SLN identification [Rousseau et al., 2005]. Failure of scintigraphic localization may be due to technical issues, the radiocolloid agent itself, or anatomic factors such as anatomic site, node characteristics, or complexities of the lymphatic drainage pattern. The surgeon should probe into whether the nuclear medicine department has noted other instances in which there was a failure to localize SLNs with the same lot of radiotracer. Other relevant questions might concern the dose of tracer employed, whether any technical problems were noted, and the duration of time from injection to detection/scanning and surgery.

There are a variety of acceptable courses when lymphoscintigraphy fails to localize any SLNs. One successful approach used in the setting of breast surgery has been reported by Meretoja and colleagues [Meretoja et al., 2010]. 207 (15.8\%) out of 1,309 patients undergoing 
lymphatic mapping were given a second injection of radiocolloid because of poor or no visualization of SLNs, and this was demonstrated to be an effective strategy for SLN identification with no apparent significant adverse effects. However, depending on the circumstances, a second injection may pose significant logistical problems for the patient, operating room, and surgeon. Alternatively, the procedure may be postponed in favor of repeating lymphoscintigraphy with SPECT/CT imaging, which provides a finer, threedimensional image of lymphatic drainage and may enhance the ability to detect SLNs in the setting of complex drainage patterns [van der Ploeg et al., 2009; Vermeeren et al, 2010]. This is more resource-intensive, however, and SPECT/CT imaging is not available at all institutions that offer lymphoscintigraphy.

Another option is to perform the procedure using blue dye alone. In breast surgery, most surgeons restrict the dissection for SLNs to the axilla regardless of the small possibility that SLNs may be located in other nodal basins, and therefore employing blue dye alone in this setting is not problematic. Melanomas, on the other hand may be located anywhere, and lymphatic drainage patterns may be difficult to predict. While the draining nodal basin for most melanomas - particularly extremity lesions - can usually be predicted, there is inherent degree of guesswork associated with this approach; hence, it simply may be too unreliable for most lesions in locations such as the trunk, head and neck. In addition, there may be a lower success rate with the application of blue dye alone for SLNB if prior lymphoscintigraphy failed to localize a SLN [Rousseau et al, 2005].

Another option is to abort pathologic nodal staging altogether, which would seem to conflict with whatever the rationale was underlying the original decision to perform the procedure. However, this is a reasonable option if in the surgeon's judgment it is in the best interest of the patient. The opposite extreme is to perform an elective lymph node dissection, and this remains an acceptable alternative, as well. However, since there remains no proof that either SLNB or complete LND improves survival in melanoma, this may represent an overly aggressive approach for most patients. Furthermore, as with attempting SLNB with blue dye alone, particularly for non-extremity melanomas, this option may be limited because of uncertainty regarding which would be the appropriate (draining) lymph nodes basins to dissect.

Another scenario that may be encountered is diffuse uptake among a large number of nodes in multiple basins and/or along a diffuse chain such as the pelvic or even para-aortic nodes. In these cases, it is important to weigh the relative benefits and risks of performing a much more extensive nodal mapping procedure than may have been planned. Certainly, there are proponents of a very aggressive approach in this setting, a viewpoint that emphasizes the value of SLNB in properly staging patients. An alternative is to routinely biopsy Cloquet's node during inguinofemoral SLNB and to use the status of Cloquet's node as a surrogate for pelvic SLNB [Essner et al., 2006]. Another option is to use the presence or absence of "second-echelon" iliac/obturator SLNs identified by lymphscintigraphy to determine whether a deep pelvic LND should be added to superficial groin dissection in the setting of a positive inguinal SLN [van der Ploeg et al., 2008]. Unfortunately, there remains no consensus regarding the best approach to managing these patients.

In situations when the surgeon believes that the risks outweigh the benefits, it is reasonable to forego performing an extensive nodal staging procedure. For example, there may be a dominant appearing SLN in the inguinal region and multiple additional faint iliac nodes on lymphoscintigraphy. In this situation, the magnitude of the procedure would be much greater and might approach the degree of dissection associated with a pelvic LND. This 
scenario would sway the surgeon away from extending the SLNB to the pelvic nodal basin. On the other hand, a young patient with a single SLN mapping to the distal external iliac nodal chain would be a more reasonable candidate for a pelvic SLNB. The other proposed strategies are also reasonable alternatives to the management of patients with lymphatic mapping to iliac/obturator nodes.

In summary, there are a variety of unexpected results and complexities that may accompany lymphatic mapping and SLNB. It is of utmost importance to plan for potential issues that arise and to counsel patients proactively so that when they do arise, patients are prepared for the recommended contingency plans. Following lymphoscintigraphy and prior to surgery, an unexpected result that could alter the operative plan should be explained to the patient and any resulting questions should be addressed before finalizing the plan. In this manner, one can ensure that the recommended course is both rational given the circumstances of the case and acceptable to the individual patient.

\section{Indication for and extent of lymph node dissection}

The potential therapeutic value of regional node dissection remains a topic of significant debate for a number of solid tumors, including melanoma. While there have been clinical trials suggesting an improvement in survival in specific subgroups of patients undergoing prophylactic lymph node dissection, whether lymph node dissection itself actually improves overall survival in melanoma remains controversial.

Historically, prior to the advent of the sentinel lymph node biopsy, two alternative strategies were applied to lymph node dissection for primary cutaneous melanoma with clinically negative nodes. One approach was to perform a complete lymph node dissection (CLND) up-front at the time of definitive surgical excision of the primary tumor; this is referred to as "early" or "prophylactic" lymph node dissection. The other strategy involved performing only the definitive wide excision up front and then carrying out surveillance for the appearance of clinically enlarged nodes; this approach is called "delayed" or "therapeutic" LND (or simply "observation").

Several randomized, prospective trials have been performed in an effort to determine which approach is superior with respect to survival [Balch et al., 2000; Cascinelli et al., 1998; Sim et al., 1986; Veronesi et al., 1977]. While each of the studies had somewhat different methodologies and inclusion criteria, none of them showed an improvement in disease-free or overall survival without subgroup analysis. It should be noted, however, that the World Health Organization (WHO) study, which included only patients with truncal melanomas at least $1.5 \mathrm{~mm}$ in thickness, did show an approximately $21 \%$ absolute improvement in fiveyear survival favoring ELND over observation when only those patients in the ELND group with positive nodes were compared to those in the observation group $(48.2 \%$ vs $26.6 \%$, p $=$ .04) [Cascinelli et al, 1998].

The Intergroup Melanoma Surgical Trial included clinically node-negative patients with 1-4 mm thick melanomas and again randomized them to ELND versus initial observation. In this trial, patients were prospectively stratified for tumor thickness, anatomic site, and the presence of ulceration. Overall 10-year survival was similar in the ELND and observation groups (77\% vs $73 \%, \mathrm{p}=.12)$. However, ELND was associated with a $30 \%$ relative reduction in 10-year mortality in non-ulcerated melanomas, $30 \%$ reduction for those with 1-2 $\mathrm{mm}$ thick melanomas, and 27\% reduction for those with extremity melanomas (all statistically significant). Also significant was a $27 \%$ relative reduction in mortality in patients age 60 
years or younger, though this was not a prospectively stratified subgroup [Balch et al, 2000]. These findings fueled the debate regarding the value of early LND for nodal metastasis and perhaps accelerated the interest in and acceptance of lymphatic mapping and sentinel lymphadenectomy for nodal staging in melanoma.

The sentinel lymph node biopsy technique was introduced as a nodal staging technique for melanoma by Don Morton and colleagues in the early 1990s [Morton et al., 1992]. Since then, numerous reports have verified its utility and reliability, have quantified its sensitivity and specificity, and have described the relative limitations and risks of the technique in the setting of melanoma and breast cancer, and an in-depth discussion of these topics is beyond the scope of this chapter. Nonetheless, while most melanoma experts agree that performance of a sentinel lymph node biopsy in appropriately selected, clinically node-negative patients provides important staging information, the question remains whether performing the technique improves survival. In the Multi-Center Selective Lymphadenectomy Trial I (MSLT-I), patients with 1-4 mm thick primary melanomas were randomized to SLNB versus observation [Morton et al., 2006]. This trial showed similar 5-year survival in both the SLNB and observation groups. However, subgroup analysis showed a $20 \%$ improvement in 5 -year survival favoring patients who underwent SLNB followed by CLND for positive nodes in comparison with patients who underwent observation and eventually required CLND for clinically positive nodes $(72.3 \%$ vs $52.4 \%, \mathrm{p}=.004)$. In this study Morton et al. also demonstrated that there was a significant difference between nodal relapse in those who were SLNB negative $(4.0 \%)$ and those who were SLNB positive but were assigned to the observation arm $(15.6 \%)$, from which the authors concluded that micrometastases would progress within regional or distant nodes. Thus, data from the WHO trial and MSLT-I have been used in support of the viewpoint that early LND when metastases are clinically occult may serve not only to improve the accuracy of staging, but may improve survival.

However, this interpretation of the results of MSLT-I has been questioned by many authors, and it remains uncertain whether SLNB or CLND may be therapeutic in melanoma. It has been pointed out that MSLT-I was underpowered to correctly analyze the survival benefit of immediate v. delayed CLND. Additionally the argument has made that it was improper to draw conclusions about survival in immediate v. delayed CLND as this was a postrandomization sub-group analysis [Ross \& Gershenwald, 2008]. The idea that all micrometastases (detected by SLNB) would ultimately develop into clinically relevant disease (i.e., palpable lymphadenopathy) has also been questioned, leading to skepticism that the subgroup comparison between SLN-positive patients and those eventually developing clinically positive nodes is a valid analysis [Hermanek et al., 1999; van Akkooi et al., 2006]. That is, perhaps some micrometastases have indolent biology and do not develop into clinically detectable nodal disease for many years. In fact, a study by Van Akkooi et al. demonstrated no overall survival benefit for immediate CLND [van Akkooi et al., 2007]. Complicating matters still further, recent studies have shown only a $50-69 \%$ rate of immediate CLND for patients with positive SLNs, which means that at least half of patients would not receive a survival benefit if indeed early CLND produced such a benefit [Bilimoria et al., 2008; Callender \& McMasters; Cormier et al., 2005; McMasters]. In fact, for the majority of patients who have micrometases only in the SLN, whether CLND is even necessary to achieve the theoretical therapeutic benefit remains in question, as well. This is being addressed in MSLT-II, in which patients with positive SLNs are randomized to CLND versus close observation [Amersi \& Morton, 2007]. Additionally, the EORTC is conducting the MINITUB trial as well to help determine the effect of timing of CLND on survival [van Akkooi et al.]. 
It is important to appreciate another level of complexity with regard to CLND following SLNB: if there is a survival benefit associated with CLND, based on the existing literature it would appear to be restricted to the subset of patients with positive SLNs. It is well documented that only about $20 \%$ of patients undergoing SLNB will have one or more SLNs with micrometastasis, and thus $80 \%$ of patients undergoing SLNB may be spared a CLND. Furthermore, among the $20 \%$ of patients with one or more "positive" SLNs, only about $20 \%$ of those patients will have additional nodes with detectable metastatic disease. Whether it is only this subgroup of node-positive patients that benefit from CLND and how to reliably predict this is unknown at the present time.

Clearly, not all "positive" SLNs are the same. SLN metastases range from isolated tumor cells identified by immunohistochemical staining alone to macroscopic metastases, and, importantly, disease burden is an important prognostic factor. Perhaps the most reliable predictor of both survival and the probability of non-SLN metastasis is the maximal diameter of the largest SLN metastasis [Francischetto et al., 2010; Guggenheim et al., 2008; Ranieri et al., 2002]. The Rotterdam Criteria for classifying SLN disease burden represents a prognostically relevant and useful strategy for stratifying patients and is based on the largest diameter of the largest metastasis in the SLN: less than $0.1 \mathrm{~mm}, 0.1-1.0 \mathrm{~mm}$, or greater than $1.0 \mathrm{~mm}$ [van der Ploeg et al., 2010]. Not only does the size of SLN metastases predict the presence of additional disease in non-SLNs, but the anatomic location of tumor deposits is predictive as well. Dewar and colleagues classified SLN metastases as subcapsular, combined subcapsular and parenchymal, parenchymal, multifocal, or extensive; subsequent CLND revealed no additional tumor-positive non-SLNS in the $26 \%$ of patients with only subcapsular SLN deposits among a total of 146 patients with positive SLNs [van der Ploeg et al, 2010]. Unfortunately, it remains a subject of controversy whether a specific size cutoff (such as $0.2 \mathrm{~mm}$ ) or other characteristic of SLN metastases is a reliable enough indicator of non-SLN status to be used as a basis for determining whether to perform or to forego CLND [Francischetto et al, 2010; Guggenheim et al, 2008]. Ongoing studies investigating the need for CLND in the setting of a positive SLN, such as MSLT-II, should provide further insight to help address this important issue.

While questions regarding the need for CLND, ideal patient selection for CLND, and potential impact of CLND on survival in melanoma have not been resolved, one aspect that has been fairly well characterized is the morbidity associated with this procedure. Inguinal as opposed to axillary LND may be associated with particularly high morbidity. Sabel and colleagues reported on 212 patients who underwent inguinal LND and observed a rate of wound complications of $19 \%$ and lymphedema of $30 \%$, both of which were significantly higher in patients with clinically positive nodes than those with microscopic nodal disease [Sabel et al., 2007]. Chang and colleagues recently reported the results of a prospective study of 53 patients undergoing inguinal LND, and they observed an overall 30-day wound complication rate of $77 \%$ [Chang et al., 2010]. Interestingly, addition of a pelvic lymph node dissection was not associated with a statistically significant increase in complication rate. Whether technical factors, such as preserving the greater saphenous vein, is associated with a lower complication rate remains uncertain [Sarnaik et al., 2009]. The leg endoscopic groin lymphadenectomy, a minimally invasive technique, is currently being evaluated as a potentially less morbid approach to inguinal lymph node dissection [Master et al., 2009].

In summary, nodal staging and the value of CLND in melanoma continue to be hotly debated topics, and important questions remain. What is known is that the SLN biopsy can provide valuable staging information that refines prognosis and may significantly impact 
clinical management. While it is unclear whether the SLNB itself and/or CLND (directly or indirectly) improve survival in patients with nodal metastasis, this remains a possibility. Therefore, although both SLNB and CLND have associated risks and costs, until the issue has been resolved, performing SLNB in appropriate candidates followed by CLND for positive nodes in acceptable-risk patients appears to be the default for most patients unless they are entered into a suitable clinical trial (such as MSLT-II). All patients should be counseled regarding the potential benefits and risks of these procedures as indicated and should be afforded the opportunity to make a proper informed decision regarding their management.

\section{Surgical management of childhood melanoma}

There is increasing appreciation that melanoma not only may arise in children and young adults, but it may be at least as aggressive as in older patients and may be increasing in incidence. A number of challenging clinical problems may arise in the management of pediatric melanomas, ranging from the diagnosis to the management of advanced disease. It is important to appreciate the potential lethality of this disease in younger patients and to ensure that fundamental principles of surgical management are applied to the pediatric population with the same degree of vigilance as they are to adults.

While the characteristics, diagnosis, and treatment of adult melanoma have been well studied, there are relatively few publications providing significant insight into the same disease in children. This section will describe some of the characteristics that are similar between childhood and adult melanoma, but also help to highlight the unique aspects of childhood melanoma, particularly in terms of diagnosis and treatment of this disease in this patient population.

\subsection{Epidemiology}

Melanoma has a current annual incidence the U.S. of over 68,000 , and approximately $1-4 \%$ of affected individuals are 19 years or younger (pediatric or "childhood" melanomas) [Ceballos et al., 1995; NCI, 2011; Prosdocimo et al., 2002]. About 75\% of these tumors occur in the 15-19 year age group [Hamre et al., 2002; Lange et al., 2007]. Males are more likely to be affected in younger age groups, and the incidence in females increases with age [Hamre et al, 2002; Lange et al, 2007]. Although head and neck melanoma is most common in ages 1-4, truncal melanomas are more common after age four [McMasters et al., 2001].

\subsection{Classification of childhood melanomas}

Childhood melanomas may be classified based on age and mechanism or route of occurence. One such system revolves around age and was reported by Jen and colleagues [Jen et al., 2009]:

- Congenital (in utero to birth)

- Infantile (birth to age 1 year)

- Childhood (1 year to puberty)

- $\quad$ Adolescent (Post Puberty)

The second such scheme is based on the origin or mode of development of melanoma [Downard et al., 2007]:

- Arising from transplacental spread

- Arising via transformation from a giant congenital melanocytic nevus 
- Arising in association with predisposing conditions

- Arising from healthy skin

- Arising from a pre-existing nevus

\subsection{Risk factors/diagnosis}

Because of the low incidence of melanoma in children and the perception that it is adult disease, it is not uncommon for a physician to overlook concerning findings that might otherwise have lead to a prompt diagnosis in an adult. Physicians should ensure that childhood melanoma is in the differential diagnosis of suspicious skin lesions, particularly when predisposing factors or conditions are present. As with adults, the size, shape and character of existing skin lesions should be noted, and a dermatologist should be consulted regarding the management of any concerning appearing pigmented lesions. Particularly at risk are children with a history of significant sun exposure or a predilection for sunburning, and those with freckles, fair skin, blue/green eyes, and/or blond/red hair [Elwood \& Jopson, 1997; Roth et al., 1990].

One condition that has a known predisposition to transformation into melanoma is that of giant congenital melanocytic nevus (GCMN). GCMN is defined as a melanocytic nevus that is greater than $20 \mathrm{~cm}$ in diameter or, alternatively, that occupies more than $2 \%$ of the body's surface area [Chung et al., 2006; Tannous et al., 2005a]. The incidence of GCMN has an incidence of approximately 1 in 20,000 newborns. Approximately 30\% of childhood melanomas arise from giant congenital melanocytic nevi, and it has been estimated that GCMN carries a $2-20 \%$ risk for malignant transformation [Fishman et al., 2002]. While prophylactic excision of GCMN remains a topic of some debate, in light of the potential lifethreatening implications associated with transformation to malignant melanoma, counseling parents regarding the potential benefits and risks of excision, at a minimum, is warranted. Importantly, the cosmetic implications of excision may be significant, and large lesions may require skin grafting or more complex plastic surgical procedures. Patients who have undergone excision of a GCMN may still develop an extracutaneous melanoma on rare occasions and therefore should undergo long-term surveillance [Krengel et al., 2008]. In addition, congenital melanocytic nevi that are not considered "giant" still carry up to a 1-5\% risk of malignant transformation, so these should also be carefully observed or, in some cases, prophylactically excised [Tannous et al., 2005b].

A rare condition that predisposes children to melanoma is xeroderma pigmentosum, which renders affected individuals 2,000 more times likely to develop melanoma than children without the condition [Pappo, 2003]. Mutation of the CDKN2A (p16) gene also dramatically increases the risk of melanoma. Although the precise incidence of childhood melanoma per se in kindreds with a CDKN2A germline mutation is unknown, there is as high as a $50-90 \%$ lifetime risk of melanoma in affected individuals [Bergenmar et al., 2009]. Finally, as is observed in adults, children who are immunosuppressed, either genetically or pharmacologically (e.g., following organ transplantation), are an estimated 3-6 times more likely to develop melanoma [Downard et al, 2007; Pappo, 2003]. As with all patients who are at elevated risk of developing melanoma, dermatology consultation and appropriate followup should be carried out for pediatric populations with these significant predispositions to melanoma and other skin cancers.

With regard to diagnosis, it should be noted that presentation of children with melanoma is often similar to that of adults, and a similar approach should be used to confirm the diagnosis of melanoma. However, the diagnosis may be difficult to establish, and delays in 
diagnosis may delay treatment in up to $40-60 \%$ of cases in children [Melnik et al., 1986; Ridha et al., 2007; Saenz et al., 1999]. Probably as a result of the diagnostic difficulty, childhood melanomas are often thicker at the time of diagnosis than melanomas occurring in adults [Ferrari et al., 2005; Rao et al., 1990; Schmid-Wendtner et al., 2002]. As noted above, one potentially valuable approach to differentiating between melanoma and a benign condition such as a Spitz nevus is to perform a sentinel lymph node biopsy [Downard et al, 2007]. Sometimes genetic testing may also be helpful, since this appears to be of potential value primarily in differentiating melanoma from Spitz nevi [Bauer \& Bastian, 2006]. Ultimately, just as in adults, clinical suspicion should drive the work-up and management of suspected melanoma in the pediatric patient population [Jen et al, 2009].

\subsection{Treatment}

With regard to treatment, the same principles of wide local excision that are used in adults apply to children, as well. In pediatric patients, there should be a low threshold for involvement of a plastic surgeon in management, especially in cosmetically or functionally sensitive areas, such as the face, joints, or genitalia. As with adults, there is a role for SLNB, and in children this can also serve a dual role of nodal staging and helping to establish the diagnosis of melanoma. In fact, children may actually be more likely to have a positive SLN than adults $-44 \%$ for children versus $24 \%$ for adults in one study [Topar \& Zelger, 2007]. Certainly, in the risk-benefit equation regarding surgical treatment, appropriate weight should be placed on the importance of early aggressive surgical extirpation and the implications of failing to do so when faced with a melanoma.

\subsection{Prognosis}

Overall the prognosis of melanoma in pediatric patients is similar to that in adults. It has been shown that there is no significant difference in the five and ten year survival rates between adults and children [Balch, 1992] or between adolescents and pre-pubescent children [Livestro et al., 2007]. One fairly large study demonstrated an overall five year disease free survival of $83.2 \%$ [Livestro et al, 2007]. In another study, the five year survival rate was $90 \%$ in 79 patients with a median Breslow thickness of $0.8 \mathrm{~mm}$ [Karlsson et al., 1998]. Age less than 10 years, male sex, and metastasis have been shown to be negative prognostic factors for survival in pediatric melanomas [Strouse et al., 2005].

\subsection{Summary}

Melanoma may occur in the pediatric population as in adults and may have a similarly aggressive course. Furthermore, there is concern that the incidence of childhood melanoma is increasing. Consequently, there should be a high level of vigilance in the screening and detection of melanoma in this population. Xeroderma pigmentosum, GCMN, and other predisposing conditions should further heighten the awareness of pediatricians and lower their threshold for early referral to a dermatologist.

Once diagnosed, the management of melanoma in children is similar to that in adults, although there is limited literature available on the topic. Although the use of wide local excision is applicable in children, the size of their lesion must be taken into consideration as large lesions might require the involvement of other surgical subspecialties for reconstructive efforts. In addition, lymphatic mapping and SLNB may play a valuable role in the diagnosis and staging of childhood melanoma. 


\section{Surgical management of melanoma in pregnancy}

Primary melanoma during pregnancy is frequently accompanied by significant emotional distress on the part of the patient and occasionally and uncertainty regarding the optimal approach to management on the part of the surgeon. In general, wide excision can be performed safely during pregnancy, and there is rarely a legitimate reason for undue delay. The dilemma usually surrounds the appropriateness and timing of sentinel lymph node evaluation and the technique of performing the procedure during pregnancy. The possibility that hormonal changes may influence the progression or management of melanoma is another topic of interest and debate.

\subsection{Hormones and melanoma}

Whether hormonal changes during pregnancy may impact the biological behavior of melanoma remains uncertain. Early studies dating back to the 1950s indicated that pregnant women with melanoma had a worse prognosis than women who were not pregnant [Driscoll \& Grant-Kels, 2007]. The belief that hormones of pregnancy could negatively impact prognosis was reinforced by investigations demonstrating the presence of estrogen receptors on melanoma cells [Neifeld \& Lippman, 1980]. However, later studies employing monoclonal antibodies refuted this finding and demonstrated that human melanoma cells do not express estrogen receptors [Flowers et al., 1987; Lecavalier et al., 1990]. However, a subsequent study showed that metastatic melanoma tissue specimens were positive for testosterone receptors, which, when activated, stimulate proliferation. These receptors also appeared to be activated by estrogen, and tamoxifen blunted the proliferative effect of estrogen on these receptors [Morvillo et al., 2002]. Importantly, the use of oral contraceptives (OCP) or hormone replacement therapy (HRT) did not appear to increase the risk of melanoma or worsen the prognosis of melanoma [Durvasula et al., 2002; MacKie, 1999; Pfahlberg et al., 1997]. While further research is warranted regarding this subject, it does not appear that exogenous hormones negatively impact prognosis in melanoma.

Although there is limited evidence because of the relative infrequency of melanoma in pregnancy, the survival of women who develop melanoma during pregnancy does not appear to be significantly different from that of women with melanoma who are not pregnant [Lens et al., 2004]. Another common concern is transplacental transmission of melanoma, but this phenomenon is extremely rare and occurs only in the setting of advanced, generally stage IV melanoma [Driscoll \& Grant-Kels, 2008]. In a recent study of 22 gravid women with advanced melanoma (10 stage III and 12 stage IV), there were no cases of neonates born with melanoma and only one case of placental metastases among 18 evaluable patients [Pages et al., 2010]. Nonetheless, women are often advised to wait approximately 2-5 years after diagnosis before conceiving. Although melanoma may recur at any point, most recurrences will occur within this time frame. Thus, waiting several years before attempting conception may provide some reassurance that the melanoma is less likely to recur during pregnancy [Leachman et al., 2007]. Such a decision, of course, is a very personal and difficult one for any woman or couple, and should be supported with accurate information and appropriate counseling.

With regard to treatment of primary cutaneous melanoma occurring during pregnancy, the mainstay of treatment remains wide excision. This should be performed in a timely fashion following diagnosis as in the nonpregnant patient and often may be performed under local anesthetic [Veronesi et al., 1988]. Lidocaine has been shown to safe in pregnancy, but 
caution should be exercised when using epinephrine [Gormley, 1990; Lawrence, 1996]. Moderate sedation, monitored anesthesia care, and general anesthesia can all be administered safely in pregnancy, and hence more extensive procedures that are not readily amenable to local anesthesia should not deter the surgeon from appropriately aggressive surgical excision and, if needed, reconstructive surgery [Kuczkowski, 2004].

\subsection{Sentinel lymph node biopsy}

Performance of nodal staging with sentinel lymphadenectomy during pregnancy remains controversial because of uncertainty regarding the risk of blue dye administration and Technetium Tc 99m sulfur colloid (radiocolloid) lymphoscintigraphy to the fetus. The most commonly employed agents for SLNB - Technetium Tc 99m sulfur colloid, isosulfan blue, and methylene blue - are all pregnancy category $\mathrm{C}$ drugs. That is, there is no (or inadequate) evidence from human or animal studies regarding teratogenicity or effects on reproductive capacity to make conclusive recommendations regarding safety in pregnancy.

With radiocolloid lymphoscintigraphy, the fetus is generally exposed to less than $5 \mathrm{mGy}$ of radiation. The Society of Nuclear Medicine recommends that a pregnancy test should be conducted if there will be exposure to greater than 50 mGy [Adelstein, 1999]. Despite this, a pregnancy test is typically performed prior to lymphoscintigraphy. While there remains uncertainty about the potential risks associated with the small amount of radioactivity used in radiocolloid lymphoscintigraphy, there is also concern regarding the use of blue dye during pregnancy. The most feared of these for all patients is a risk of anaphylaxis associated with the use of isosulfan blue, estimated to be as high as $1.1 \%$, but closer to $0.1 \%$ in more recent and larger studies, and zero among the more than 2100 patients who underwent SLNB in the Sunbelt Melanoma Trial [Albo et al., 2001; Amr et al., 2005; Leong et al., 2000; Schwartz et al., 2003; Wilke et al., 2006; Wrightson et al, 2003]. Nonetheless, there is some hesitance about using the dye in patients who are pregnant based on this concern alone [Amersi \& Hansen, 2006]. There are some centers that will only employ radiocolloid in SLNB due to the risk of anaphylaxis [Lederman \& Sober, 1985]. Although anaphylaxis has been reported as a risk of methylene blue during SLNB, as well, this seems to be a very rare event [Jangjoo et al., 2010; Soni et al., 2009; Sutherland et al., 2009]. Another primary concern is the risk of teratogenicity, but as stated, this has not been precisely determined. Of note, a small study conducted by Mondi et al. where in which nine pregnant patients were exposed to the isosulfan blue dye and/or radiocolloid showed that there was no negative effect on the fetus at birth [Mondi et al., 2007].

In absence of guidance from quality scientific studies, the performance of SLNB with vital dyes and/or radiocolloid during pregnancy should be determined on an individual basis. Among the many considerations is location of the primary site; if the primary tumor is located on the abdomen, one must appreciate that, in concept, the direct local exposure of the fetus to radioactivity from a radiocolloid injection may be higher than the systemic exposure, though the precise level of exposure has not been established. If this is a concern, then using a smaller quantity of radiocolloid and performing the procedure as soon as is feasible following completion of lymphoscintigraphy are reasonable measures to minimize radiation exposure of the fetus. For patients in whom there is greater concern for lymph node metastasis, then performing a SLNB should receive a higher priority. While the use of isosulfan blue dye and radiocolloid should be considered, it is also reasonable to use only a single agent in order to decrease risk - generally radiocolloid for most melanomas, 
particularly when there is uncertainty regarding the location (and number) of draining lymph node basin(s).

Another option is to perform wide excision up-front and to postpone the SLNB until after delivery. While it is uncertain whether postponement of SLNB until the end of pregnancy may negatively impact prognosis, there are no published studies confirming this. There is evidence from a multicenter study of 76 patients that the performance of SLNB after definitive wide excision, when necessary, does not diminish the accuracy of the SLNB [Evans et al., 2003]. If radiocolloid is employed in SLNB during the postpartum period, breast-feeding mothers should have alternative plans for feeding for a few days after the procedure until the radioactivity has been cleared, as the half-life for radioactive decay of Technetium Tc $99 \mathrm{~m}$ is approximately 6 hours. In all cases the potential risks of these therapies should be thoroughly discussed with the expecting mother or couple. In pointing out the potential benefits and risks, it should be stressed that, while a SLNB provides valuable staging information, it has not been shown to improve survival in patients undergoing the procedure. Clearly, further research and long-term data on the risks and benefits of SLNB in pregnancy would be needed before more definitive guidelines can be established.

\section{The role of surgery in the management of advanced melanoma}

Surgical procedures may be beneficial in the palliation and/or control of disease in advanced melanoma, including either locoregionally advanced or distant metastatic disease. There is ample literature justifying resection of stage IV disease when feasible, and this has recently been reviewed in depth [Mosca et al., 2008]. Selection of the appropriate clinical scenario and particular patient amenable to surgical intervention, however, can present challenging management problems. Regardless of the circumstances, in considering a role for surgery in the care of the advanced melanoma patient, it is vital to clearly establish the goal(s) of surgery and to carefully weigh surgery versus other alternatives.

Advanced melanoma may take a variety of forms, and the particular pattern of disease and biologic behavior, as well as standard patient factors, should drive the management strategy for each individual patient. Certainly, participation in clinical trials is encouraged for all eligible and interested patients. Some patients present with widespread and/or rapidly progressive distant metastases and typically are candidates only for palliative systemic therapy or supportive care alone, though surgery (or other treatment) is sometimes indicated for palliation of a specific symptom complex. Surgical intervention for the purpose of eradicating disease - which may also achieve symptom control - is generally contemplated in the context of relatively indolent locoregionally advanced and/or distant disease, typically involving only one or a limited number of sites (oligometastatic melanoma).

\subsection{Resection of distant metastatic disease}

Surgical resection for stage IV melanoma should be considered in appropriate patients. When complete resection is performed in the setting of distant disease, five-year survival rates in the range of $20-25 \%$, and as high as $40 \%$, may be achieved [Mosca et al, 2008]. Importantly, one study showed that, while patients who undergo complete resection of metastatic melanoma have a 5 year survival rate of $23 \%$, the figure was $6 \%$ in patients who either do not undergo surgery or have gross residual disease remaining following surgery (R2 resection) [Agrawal et al., 1999; Essner et al., 2004; Ollila et al., 1996; Rose et al., 2001]. 
As with almost all major oncologic procedures, a key to achieving optimal outcomes is proper patient selection. For example, patients with a disease-free interval of greater than 36 months at the time of recurrence and those with a solitary metastasis have better outcomes a [Essner, 2003; Essner et al, 2004]. Tumor doubling time has also been correlated with prognosis; a tumor doubling time of greater than 60 days is associated with a more favorable prognosis relative to a shorter doubling time [Ollila et al., 1998].

Among the most important factors to consider with regard to resection of advanced stage melanoma is that of location. The locations of metastasis that confer the best chance of survival are skin, subcutaneous tissue, and/or lymph nodes, with resection of these metastases being associated with a median survival of 24 months [Ollila et al., 1999].

In contrast, visceral metastases are associated with a worse prognosis in comparison with that of skin/soft tissue/nodal metastases. Among visceral sites, metastasis to the lungs is associated with the longest survival. Factors that are positively associated with prognosis for resection of lung metastasis are ability to perform complete resection, a prolonged diseasefree interval, one or two pulmonary nodules, prior response to chemotherapy, negative lymph nodes, and the absence of extrathoracic disease [Harpole et al., 1992; Petersen et al., 2007]. Metastasectomy is associated with a median survival of 20 months compared with only 7.2 months for patients who do not undergo surgical resection [Young et al., 2006].

When there is metastasis to the gastrointestinal tract, surgery is often limited to palliative measures for patients experiencing perforation, obstruction, or bleeding. A more aggressive approach should be taken to resection when there may be a potential survival benefit, such as when it appears that the metastasis can be completely excised (i.e. solitary metastasis) with acceptable risk [Schuchter et al., 2000; Wood et al., 2001]. The median survival for patients with gastrointestinal metastases is 5-11 months [Panagiotou et al., 2002], but there are reports of survival of many years in a minority of patients [Young et al, 2006]. Cholecystectomy, liver resection, pancreaticoduodenectomy, or other complex pancreaticobiliary surgical procedures may also be indicated for metastatic melanoma to those sites [Carboni et al., 2004; Cellerino et al., 2000; Rose et al, 2001]. Another site of metastasis for which complete resection may be associated with a significant survival benefit is that of the adrenal gland. In cases of complete resection, median survival is 25.7 months compared to only 9.2 months for palliative resection [Haigh et al., 1999]. Alternatively, stereotactic radiosurgery may provide significant benefit in terms of disease control or palliation of symptoms related to brain or spinal cord metastasis. However, the prognosis is poor with most studies demonstrating a median survival of 5-10 months [Gaudy-Marqueste et al., 2006; Mathieu et al., 2007; Powell et al., 2008; Samlowski et al., 2007; Tarhini \& Agarwala, 2004].

\subsection{Surgical management of advanced extremity melanoma}

Advanced melanoma of the extremity may take the form of bulky and/or in transit disease. While this pattern may be amenable to surgical extirpation or palliation with intralesional injection of an immune modulator such as BCG [Storm et al., 1979], usually its pace rapidly advances beyond the ability to control it with local treatments. An effective approach to these cases is regional chemotherapy in the form of hyperthermic isolated limb perfusion (HILP) or a less invasive alternative called isolated limb infusion (ILI) [Ariyan \& Brady, 2008; Padussis et al., 2008; Tyler \& Ross, 2008].

Regional therapy for advanced melanoma (either HILP or ILI) can provide excellent disease control and may achieve long-term survival in a significant minority of patients with 
advanced extremity melanoma [Alexander et al., 2010; Grunhagen et al., 2006; Kroon et al., 2008; Lindner et al., 2002; Rossi et al., 2010; Sanki et al., 2007]. While a relatively wide range of response rates have been reported, these procedures, both of which usually employ a melphalan-based regimen, yield objective responses in the majority of patients. HILP has been reported to achieve overall and complete response rates of as high as $80-100 \%$ and $60-$ $90 \%$, respectively [Ariyan \& Brady, 2008; Tyler \& Ross, 2008]. In a randomized, prospective, multicenter U.S.-based cooperative group trial (ACOSOG Z0020) examining HILP with melphalan $+/-$ TNF- $\alpha$, the overall and complete response rates were more modest at $66 \%$ and $25 \%$ with no difference between the TNF- $\alpha$ and melphalan alone groups [Cornett et al., 2006].

ILI is a less invasive form of regional chemotherapy for the treatment of advanced extremity melanoma that has been reported to achieve overall and complete response rates as high as $85 \%$ and $41 \%$, respectively [Lindner et al, 2002]. A recently reported multi-institutional U.S. study demonstrated a $64 \%$ overall and $31 \%$ complete response rates [Beasley et al., 2009a]. Unlike HILP, ILI does not require open surgical cannulation of vessels, but rather involves placement of catheters using a percutaneous interventional radiologic approach. Thus, while a lymph node dissection of the relevant basin, if not previously done, is typically performed as part of the exposure for HILP, it must be added as an additional procedure if necessary either under the same anesthetic as for ILI or in a staged fashion.

While rare systemic side effects may occur and mild to moderate skin/soft tissue toxicity are common, primary complications of concern are compartment syndrome, occurring in about $10 \%$ and limb loss occurring in up to $2 \%$ of patients. Regional chemotherapy may also be used to effectively palliate advanced extremity disease in the setting of stage IV melanoma [Kroon et al., 2009]. In ACOSOG Z0020, the incidence of grade 4 regional toxicity was $12 \%$ and was higher in the TNF- $\alpha$ group; and two out of 129 patients $(1.6 \%)$, both in the TNF- $\alpha$ group, required amputation due to regional toxicity [Cornett et al, 2006]. While both HILP and ILI are effective therapies for controlling or eradicating extremity melanoma, ILI is a less invasive method that is associated with lower regional toxicity, but it is also a somewhat less effective alternative than HILP [Beasley et al., 2008].

Recently, novel approaches to enhancing the efficacy of regional chemotherapy have been investigated. One intriguing approach is to combine systemically administered targeted molecular therapies with conventional regional chemotherapy. Beasley and colleagues reported the results of a phase 1 dose-escalation trial of systemic ADH-1, an inhibitor of the adhesion molecule N-cadherin, in conjunction with ILI, and the treatment was well tolerated and yielded a robust complete response rate [Beasley et al., 2009b]. This was followed up with a phase II study, but no significant improvement in objective response rate was noted [Beasley et al., 2011]. However, this work introduced a new paradigm for the development of novel cytotoxic and targeted molcular therapeutics for the treatment of advanced melanoma. Another significant advancement is the emergence of gene expression profiling of tumor biopsies - usually readily accessible in this patient population - as a potential means of predicting treatment response and guiding selection of optimal therapeutics for regional chemotherapy [Augustine et al., 2010].

Invasive or minimally invasive surgical interventions may be indicated in a variety of settings for the treatment of advanced melanoma. The goal may be to achieve prolonged disease control or to palliate specific symptoms or some combination of the two. One should carefully select patients for major intervention so that the right patients receive the right treatment at the right time. Certainly, performing a major surgical procedure associated 
with significant risk and without clear benefit has the potential to shorten life and/or worsen the quality of life of a patient and therefore have the opposite consequences to those intended.

\section{Conclusion}

The surgical management of cutaneous melanoma can be challenging even in relatively straightforward cases because of its protean clinical presentations, variable location, and the wide range of demographic groups that it commonly affects. However, there are a number of recurring themes in surgery for melanoma that serve as a constant reminder that some clinical problems seem to have more questions than answers. Several of these complex areas of melanoma management have been reviewed in this chapter on challenging problems. Common threads that run through these areas of uncertainty are that optimal care first necessitates familiarity with current literature and guidelines on the topic, that patients should be properly educated and actively involved in the decision-making process, and that conscientious, multi-disciplinary cancer care serves as a foundation for proper clinical management. Despite this, in the case of each of the topics discussed, there remains a tension between taking an aggressive approach to a disease that in most cases may only be cured or effectively controlled with surgery, and trying to minimize the risk of sometimes debilitating morbidity that may accompany such treatment. A thoughtful, collaborative and patient-centered approach to these challenging cases helps to ensure that each patient receives the best possible surgical management for his or her melanoma.

\section{References}

Adelstein SJ. 1999. Administered radionuclides in pregnancy. Teratology 59:236-9

Agrawal S, Yao TJ, Coit DG. 1999. Surgery for melanoma metastatic to the gastrointestinal tract. Annals of Surgical Oncology 6:336-44

Albo D, Wayne JD, Hunt KK, Rahlfs TF, Singletary SE, et al. 2001. Anaphylactic reactions to isosulfan blue dye during sentinel lymph node biopsy for breast cancer. American Journal of Surgery 182:393-8

Alex JC, Krag DN, Harlow SP, Meijer S, Loggie BW, et al. 1998. Localization of regional lymph nodes in melanomas of the head and neck. Arch Otolaryngol Head Neck Surg 124:135-40

Alexander HR, Jr., Fraker DL, Bartlett DL, Libutti SK, Steinberg SM, et al. 2010. Analysis of factors influencing outcome in patients with in-transit malignant melanoma undergoing isolated limb perfusion using modern treatment parameters. Journal of Clinical Oncology 28:114-8

Amersi F, Hansen NM. 2006. The benefits and limitations of sentinel lymph node biopsy. Curr Treat Options Oncol 7:141-51

Amersi F, Morton DL. 2007. The role of sentinel lymph node biopsy in the management of melanoma. Advances in Surgery 41:241-56

Amr D, Broderick-Villa G, Haigh PI, Guenther JM, DiFronzo LA. 2005. Adverse drug reactions during lymphatic mapping and sentinel lymph node biopsy for solid neoplasms. American Surgeon 71:720-4 
Ariyan CE, Brady MS. 2008. History of regional chemotherapy for cancer of the extremities. International Journal of Hyperthermia 24:185-92

Augustine CK, Jung S-H, Sohn I, Yoo JS, Yoshimoto Y, et al. 2010. Gene expression signatures as a guide to treatment strategies for in-transit metastatic melanoma. Molecular Cancer Therapeutics 9:779-90

Bagaria SP, Faries MB, Morton DL. 2010. Sentinel node biopsy in melanoma: technical considerations of the procedure as performed at the John Wayne Cancer Institute. Journal of Surgical Oncology 101:669-76

Balch CM. 1992. Cutaneous melanoma: prognosis and treatment results worldwide. Semin Surg Oncol 8:400-14

Balch CM, Gershenwald JE, Soong S-J, Thompson JF, Atkins MB, et al. 2009. Final version of 2009 AJCC melanoma staging and classification. Journal of Clinical Oncology 27:6199206

Balch CM, Soong S, Ross MI, Urist MM, Karakousis CP, et al. 2000. Long-term results of a multi-institutional randomized trial comparing prognostic factors and surgical results for intermediate thickness melanomas (1.0 to $4.0 \mathrm{~mm})$. Intergroup Melanoma Surgical Trial. Annals of Surgical Oncology 7:87-97

Barnhill RL, Argenyi ZB, From L, Glass LF, Maize JC, et al. 1999. Atypical Spitz nevi/tumors: lack of consensus for diagnosis, discrimination from melanoma, and prediction of outcome. Hum Pathol 30:513-20

Bastian BC, Kashani-Sabet M, Hamm H, Godfrey T, Moore DH, 2nd, et al. 2000. Gene amplifications characterize acral melanoma and permit the detection of occult tumor cells in the surrounding skin. Cancer Res 60:1968-73

Bastian BC, Olshen AB, LeBoit PE, Pinkel D. 2003. Classifying melanocytic tumors based on DNA copy number changes. Am J Pathol 163:1765-70

Bauer J, Bastian BC. 2006. Distinguishing melanocytic nevi from melanoma by DNA copy number changes: comparative genomic hybridization as a research and diagnostic tool. Dermatol Ther 19:40-9

Beasley GM, Caudle A, Petersen RP, McMahon NS, Padussis J, et al. 2009a. A multiinstitutional experience of isolated limb infusion: defining response and toxicity in the US. Journal of the American College of Surgeons 208:706-15; discussion 15-7

Beasley GM, McMahon N, Sanders G, Augustine CK, Selim MA, et al. 2009b. A phase 1 study of systemic ADH-1 in combination with melphalan via isolated limb infusion in patients with locally advanced in-transit malignant melanoma. Cancer 115:476674

Beasley GM, Petersen RP, Yoo J, McMahon N, Aloia T, et al. 2008. Isolated limb infusion for in-transit malignant melanoma of the extremity: a well-tolerated but less effective alternative to hyperthermic isolated limb perfusion. Annals of Surgical Oncology 15:2195-205

Beasley GM, Riboh JC, Augustine CK, McMahon N, Grobmyer SR, et al. 2011. A multicenter phase II trial of systemic ADH-1 in combination with melphalan via isolated limb infusion (M-ILI) in patients with advanced extremity melanoma. Journal of Clinical Oncology 29:1210-5 
Bergenmar M, Hansson J, Brandberg Y. 2009. Family members' perceptions of genetic testing for malignant melanoma--a prospective interview study. European Journal of Oncology Nursing 13:74-80

Berk DR, Johnson DL, Uzieblo A, Kiernan M, Swetter SM. 2005. Sentinel lymph node biopsy for cutaneous melanoma: the Stanford experience, 1997-2004. Arch Dermatol 141:1016-22

Berk DR, LaBuz E, Dadras SS, Johnson DL, Swetter SM. 2010. Melanoma and melanocytic tumors of uncertain malignant potential in children, adolescents and young adults-the Stanford experience 1995-2008. Pediatric Dermatology 27:244-54

Bilimoria KY, Balch CM, Bentrem DJ, Talamonti MS, Ko CY, et al. 2008. Complete lymph node dissection for sentinel node-positive melanoma: assessment of practice patterns in the United States. Ann Surg Oncol 15:1566-76

Callender GG, McMasters KM. Early versus delayed complete lymphadenectomy in melanoma: insight from MSLT I. Ann Surg Oncol 18:306-8

Carboni F, Graziano F, Lonardo MT, Lepiane P, Santoro R, et al. 2004. Pancreaticoduodenectomy for pancreatic metastatic melanoma. Journal of Experimental \& Clinical Cancer Research 23:539-43

Carless MA, Griffiths LR. 2008. Cytogenetics of melanoma and nonmelanoma skin cancer. Adv Exp Med Biol 624:227-40

Carlson GW, Murray DR, Greenlee R, Alazraki N, Fry-Spray C, et al. 2000. Management of malignant melanoma of the head and neck using dynamic lymphoscintigraphy and gamma probe-guided sentinel lymph node biopsy. Arch Otolaryngol Head Neck Surg 126:433-7

Carlson GW, Murray DR, Hestley A, Staley CA, Lyles RH, Cohen C. 2003. Sentinel lymph node mapping for thick (>or=4-mm) melanoma: should we be doing it? Annals of Surgical Oncology 10:408-15

Carlson GW, Page AJ, Cohen C, Parker D, Yaar R, et al. 2008. Regional recurrence after negative sentinel lymph node biopsy for melanoma. Annals of Surgery 248:378-86

Cascinelli N, Morabito A, Santinami M, MacKie RM, Belli F. 1998. Immediate or delayed dissection of regional nodes in patients with melanoma of the trunk: a randomised trial. WHO Melanoma Programme. Lancet 351:793-6

Casorzo L, Luzzi C, Nardacchione A, Picciotto F, Pisacane A, Risio M. 2005. Fluorescence in situ hybridization (FISH) evaluation of chromosomes 6, 7, 9 and 10 throughout human melanocytic tumorigenesis. Melanoma Res 15:155-60

Ceballos PI, Ruiz-Maldonado R, Mihm MC, Jr. 1995. Melanoma in children. N Engl J Med 332:656-62

Cecchi R, Buralli L, Innocenti S, De Gaudio C. 2007. Sentinel lymph node biopsy in patients with thin melanomas. Journal of Dermatology 34:512-5

Cecchi R, Pavesi M, Buralli L, Innocenti S, De Gaudio C. 2008. Tumour regression does not increase the risk of sentinel node involvement in thin melanomas. Chirurgia Italiana 60:257-60

Cellerino P, Corsi F, Morandi E, Foschi D, Trabucchi E. 2000. Metastatic melanoma of the gallbladder. European Journal of Surgical Oncology 26:815-6 
Chang SB, Askew RL, Xing Y, Weaver S, Gershenwald JE, et al. 2010. Prospective assessment of postoperative complications and associated costs following inguinal lymph node dissection (ILND) in melanoma patients. Annals of Surgical Oncology 17:2764-72

Cherpelis BS, Haddad F, Messina J, Cantor AB, Fitzmorris K, et al. 2001. Sentinel lymph node micrometastasis and other histologic factors that predict outcome in patients with thicker melanomas. J Am Acad Dermatol 44:762-6

Chung C, Forte AJV, Narayan D, Persing J. 2006. Giant nevi: a review. Journal of Craniofacial Surgery 17:1210-5

Cormier JN, Xing Y, Ding M, Lee JE, Mansfield PF, et al. 2005. Population-based assessment of surgical treatment trends for patients with melanoma in the era of sentinel lymph node biopsy. J Clin Oncol 23:6054-62

Cornett WR, McCall LM, Petersen RP, Ross MI, Briele HA, et al. 2006. Randomized multicenter trial of hyperthermic isolated limb perfusion with melphalan alone compared with melphalan plus tumor necrosis factor: American College of Surgeons Oncology Group Trial Z0020. Journal of Clinical Oncology 24:4196-201

De Rosa N, Lyman GH, Silbermins D, Valsecchi MD, Pruitt SK, et al. 2011. Sentinel node biopsy for head and neck melanoma: a systematic review. In press

Downard CD, Rapkin LB, Gow KW. 2007. Melanoma in children and adolescents. Surg Oncol 16:215-20

Driscoll MS, Grant-Kels JM. 2007. Hormones, nevi, and melanoma: an approach to the patient. J Am Acad Dermatol 57:919-31; quiz 32-6

Driscoll MS, Grant-Kels JM. 2008. Melanoma and pregnancy. Giornale Italiano di Dermatologia e Venereologia 143:251-7

Durvasula R, Ahmed SM, Vashisht A, Studd JW. 2002. Hormone replacement therapy and malignant melanoma: to prescribe or not to prescribe? Climacteric 5:197-200

Eicher SA, Clayman GL, Myers JN, Gillenwater AM. 2002. A prospective study of intraoperative lymphatic mapping for head and neck cutaneous melanoma. Arch Otolaryngol Head Neck Surg 128:241-6

Elwood JM, Jopson J. 1997. Melanoma and sun exposure: an overview of published studies. Int J Cancer 73:198-203

Essner R. 2003. Surgical treatment of malignant melanoma. Surg Clin North Am 83:109-56

Essner R. 2010. Lymphatic mapping and sentinel lymphadenectomy in primary cutaneous melanoma. Expert Review of Anticancer Therapy 10:723-8

Essner R, Chung MH, Bleicher R, Hsueh E, Wanek L, Morton DL. 2002. Prognostic implications of thick (>or $=4-\mathrm{mm}$ ) melanoma in the era of intraoperative lymphatic mapping and sentinel lymphadenectomy. Ann Surg Oncol 9:754-61

Essner R, Lee JH, Wanek LA, Itakura H, Morton DL. 2004. Contemporary surgical treatment of advanced-stage melanoma. Archives of Surgery 139:961-6; discussion 6-7

Essner R, Scheri R, Kavanagh M, Torisu-Itakura H, Wanek LA, Morton DL. 2006. Surgical management of the groin lymph nodes in melanoma in the era of sentinel lymph node dissection. Archives of Surgery 141:877-82; discussion 82-4

Evans HL, Krag DN, Teates CD, Patterson JW, Meijer S, et al. 2003. Lymphoscintigraphy and sentinel node biopsy accurately stage melanoma in patients presenting after wide local excision. Annals of Surgical Oncology 10:416-25 
Even-Sapir E, Lerman H, Lievshitz G, Khafif A, Fliss DM, et al. 2003. Lymphoscintigraphy for sentinel node mapping using a hybrid SPECT/CT system. Journal of Nuclear Medicine 44:1413-20

Ferrari A, Bono A, Baldi M, Collini P, Casanova M, et al. 2005. Does melanoma behave differently in younger children than in adults? A retrospective study of 33 cases of childhood melanoma from a single institution. Pediatrics 115:649-54

Ferrone CR, Panageas KS, Busam K, Brady MS, Coit DG. 2002. Multivariate prognostic model for patients with thick cutaneous melanoma: importance of sentinel lymph node status. Ann Surg Oncol 9:637-45

Fishman C, Mihm MC, Jr., Sober AJ. 2002. Diagnosis and management of nevi and cutaneous melanoma in infants and children. Clin Dermatol 20:44-50

Flowers JL, Seigler HF, McCarty KS, Sr., Konrath J, McCarty KS, Jr. 1987. Absence of estrogen receptor in human melanoma as evaluated by a monoclonal antiestrogen receptor antibody. Arch Dermatol 123:764-5

Francischetto T, Spector N, Neto Rezende JF, de Azevedo Antunes M, de Oliveira Romano $\mathrm{S}$, et al. 2010. Influence of sentinel lymph node tumor burden on survival in melanoma. Annals of Surgical Oncology 17:1152-8

Gajdos C, Griffith KA, Wong SL, Johnson TM, Chang AE, et al. 2009. Is there a benefit to sentinel lymph node biopsy in patients with T4 melanoma? Cancer 115:5752-60

Garbe C, Peris K, Hauschild A, Saiag P, Middleton M, et al. 2010. Diagnosis and treatment of melanoma: European consensus-based interdisciplinary guideline. European Journal of Cancer 46:270-83

Gaudy-Marqueste C, Regis J-M, Muracciole X, Laurans R, Richard M-A, et al. 2006. GammaKnife radiosurgery in the management of melanoma patients with brain metastases: a series of 106 patients without whole-brain radiotherapy. International Journal of Radiation Oncology, Biology, Physics 65:809-16

Gerami P, Jewell SS, Morrison LE, Blondin B, Schulz J, et al. 2009. Fluorescence in situ hybridization (FISH) as an ancillary diagnostic tool in the diagnosis of melanoma. Am J Surg Pathol 33:1146-56

Gershenwald JE, Mansfield PF, Lee JE, Ross MI. 2000. Role for lymphatic mapping and sentinel lymph node biopsy in patients with thick ( $>$ or $=4 \mathrm{~mm}$ ) primary melanoma. Ann Surg Oncol 7:160-5

Ghazi B, Carlson GW, Murray DR, Gow KW, Page A, et al. 2010. Utility of lymph node assessment for atypical spitzoid melanocytic neoplasms. Annals of Surgical Oncology 17:2471-5

Gomez-Rivera F, Santillan A, McMurphey AB, Paraskevopoulos G, Roberts DB, et al. 2008. Sentinel node biopsy in patients with cutaneous melanoma of the head and neck: recurrence and survival study. Head \& Neck 30:1284-94

Gormley DE. 1990. Cutaneous surgery and the pregnant patient. J Am Acad Dermatol 23:26979

Grunhagen DJ, de Wilt JHW, Graveland WJ, Verhoef C, van Geel AN, Eggermont AMM. 2006. Outcome and prognostic factor analysis of 217 consecutive isolated limb perfusions with tumor necrosis factor-alpha and melphalan for limb-threatening soft tissue sarcoma. Cancer 106:1776-84 
Guggenheim M, Dummer R, Jung FJ, Mihic-Probst D, Steinert H, et al. 2008. The influence of sentinel lymph node tumour burden on additional lymph node involvement and disease-free survival in cutaneous melanoma--a retrospective analysis of 392 cases. British Journal of Cancer 98:1922-8

Haigh PI, Essner R, Wardlaw JC, Stern SL, Morton DL. 1999. Long-term survival after complete resection of melanoma metastatic to the adrenal gland. Annals of Surgical Oncology 6:633-9

Hamre MR, Chuba P, Bakhshi S, Thomas R, Severson RK. 2002. Cutaneous melanoma in childhood and adolescence. Pediatr Hematol Oncol 19:309-17

Harpole DH, Jr., Johnson CM, Wolfe WG, George SL, Seigler HF. 1992. Analysis of 945 cases of pulmonary metastatic melanoma. J Thorac Cardiovasc Surg 103:743-8; discussion $8-50$

Hermanek P, Hutter RV, Sobin LH, Wittekind C. 1999. International Union Against Cancer. Classification of isolated tumor cells and micrometastasis. Cancer 86:2668-73

Jacobs IA, Chang CK, Salti GI. 2004. Role of sentinel lymph node biopsy in patients with thick (>4 mm) primary melanoma. Am Surg 70:59-62

Jangjoo A, Forghani MN, Mehrabibahar M, Sadeghi R. 2010. Anaphylaxis reaction of a breast cancer patient to methylene blue during breast surgery with sentinel node mapping. Acta Oncologica 49:877-8

Jansen L, Koops HS, Nieweg OE, Doting MH, Kapteijn BA, et al. 2000. Sentinel node biopsy for melanoma in the head and neck region. Head Neck 22:27-33

Jen M, Murphy M, Grant-Kels JM. 2009. Childhood melanoma. Clin Dermatol 27:529-36

Karakousis GC, Gimotty PA, Botbyl JD, Kesmodel SB, Elder DE, et al. 2006. Predictors of regional nodal disease in patients with thin melanomas. Annals of Surgical Oncology 13:533-41

Karlsson P, Boeryd B, Sander B, Westermark P, Rosdahl I. 1998. Increasing incidence of cutaneous malignant melanoma in children and adolescents 12-19 years of age in Sweden 1973-92. Acta Dermato-Venereologica 78:289-92

Kelly J, Fogarty K, Redmond HP. 2009. A definitive role for sentinel lymph node mapping with biopsy for cutaneous melanoma of the head and neck. Surgeon 7:336-9

Kesmodel SB, Karakousis GC, Botbyl JD, Canter RJ, Lewis RT, et al. 2005. Mitotic rate as a predictor of sentinel lymph node positivity in patients with thin melanomas. Annals of Surgical Oncology 12:449-58

Klop WM, Veenstra HJ, Vermeeren L, Nieweg OE, Balm AJ, Lohuis PJ. 2011. Assessment of lymphatic drainage patterns and implications for the extent of neck dissection in head and neck melanoma patients. J Surg Oncol

Krengel S, Breuninger H, Hauschild A, Hoger P, Merl V, Hamm H. 2008. Installation of a network for patients with congenital melanocytic nevi in German-speaking countries. Journal der Deutschen Dermatologischen Gesellschaft 6:204-8

Kroon HM, Lin DY, Kam PCA, Thompson JF. 2009. Isolated limb infusion as palliative treatment for advanced limb disease in patients with AJCC stage IV melanoma. Annals of Surgical Oncology 16:1193-201

Kroon HM, Moncrieff M, Kam PCA, Thompson JF. 2008. Outcomes following isolated limb infusion for melanoma. A 14-year experience. Annals of Surgical Oncology 15:3003-13 
Kuczkowski KM. 2004. Nonobstetric surgery during pregnancy: what are the risks of anesthesia? Obstetrical \& Gynecological Survey 59:52-6

Lange JR, Palis BE, Chang DC, Soong SJ, Balch CM. 2007. Melanoma in children and teenagers: an analysis of patients from the National Cancer Data Base. J Clin Oncol 25:1363-8

Lawrence C. 1996. Drug management in skin surgery. Drugs 52:805-17

Leachman SA, Jackson R, Eliason MJ, Larson AA, Bolognia JL. 2007. Management of melanoma during pregnancy. Dermatol Nurs 19:145-52, 61

Lecavalier MA, From L, Gaid N. 1990. Absence of estrogen receptors in dysplastic nevi and malignant melanoma. J Am Acad Dermatol 23:242-6

Lens MB, Rosdahl I, Ahlbom A, Farahmand BY, Synnerstad I, et al. 2004. Effect of pregnancy on survival in women with cutaneous malignant melanoma. J Clin Oncol 22:4369-75

Leong SP, Donegan E, Heffernon W, Dean S, Katz JA. 2000. Adverse reactions to isosulfan blue during selective sentinel lymph node dissection in melanoma. Annals of Surgical Oncology 7:361-6

Lindner P, Doubrovsky A, Kam PCA, Thompson JF. 2002. Prognostic factors after isolated limb infusion with cytotoxic agents for melanoma. Annals of Surgical Oncology 9:127-36

Livestro DP, Kaine EM, Michaelson JS, Mihm MC, Haluska FG, et al. 2007. Melanoma in the young: differences and similarities with adult melanoma: a case-matched controlled analysis. Cancer 110:614-24

Lucci A, McCall LM, Beitsch PD, Whitworth PW, Reintgen DS, et al. 2007. Surgical complications associated with sentinel lymph node dissection (SLND) plus axillary lymph node dissection compared with SLND alone in the American College of Surgeons Oncology Group Trial Z0011. Journal of Clinical Oncology 25:3657-63

Ludgate MW, Fullen DR, Lee J, Lowe L, Bradford C, et al. 2009. The atypical Spitz tumor of uncertain biologic potential: a series of 67 patients from a single institution. Cancer 115:631-41

MacKie RM. 1999. Pregnancy and exogenous hormones in patients with cutaneous malignant melanoma. Curr Opin Oncol 11:129-31

MacNeill KN, Ghazarian D, McCready D, Rotstein L. 2005. Sentinel lymph node biopsy for cutaneous melanoma of the head and neck. Annals of Surgical Oncology 12:726-32

Magro CM, Crowson AN, Mihm MC, Jr., Gupta K, Walker MJ, Solomon G. 2010. The dermal-based borderline melanocytic tumor: a categorical approach. Journal of the American Academy of Dermatology 62:469-79

Master V, Ogan K, Kooby D, Hsiao W, Delman K. 2009. Leg endoscopic groin lymphadenectomy (LEG procedure): step-by-step approach to a straightforward technique. European Urology 56:821-8

Mathieu D, Kondziolka D, Cooper PB, Flickinger JC, Niranjan A, et al. 2007. Gamma knife radiosurgery in the management of malignant melanoma brain metastases. Neurosurgery 60:471-81; discussion 81-2

McMasters KM. Why does no one want to perform lymph node dissection anymore? Ann Surg Oncol 17:358-61 
McMasters KM, Reintgen DS, Ross MI, Gershenwald JE, Edwards MJ, et al. 2001. Sentinel lymph node biopsy for melanoma: controversy despite widespread agreement. $J$ Clin Oncol 19:2851-5

Melnik MK, Urdaneta LF, Al-Jurf AS, Foucar E, Jochimsen PR, Soper RT. 1986. Malignant melanoma in childhood and adolescence. American Surgeon 52:142-7

Meretoja TJ, Joensuu H, Heikkila PS, Leidenius MH. 2010. Safety of sentinel node biopsy in breast cancer patients who receive a second radioisotope injection after visualization failure in lymphoscintigraphy. Journal of Surgical Oncology 102:649-55

Meyers MO, Yeh JJ, Deal AM, Byerly FL, Woosley JT, et al. 2010. Age and Breslow depth are associated with a positive sentinel lymph node in patients with cutaneous melanocytic tumors of uncertain malignant potential. Journal of the American College of Surgeons 211:744-8

Mondi MM, Cuenca RE, Ollila DW, Stewart JHt, Levine EA. 2007. Sentinel lymph node biopsy during pregnancy: initial clinical experience. Ann Surg Oncol 14:218-21

Morey AL, Murali R, McCarthy SW, Mann GJ, Scolyer RA. 2009. Diagnosis of cutaneous melanocytic tumours by four-colour fluorescence in situ hybridisation. Pathology 41:383-7

Morton DL, Thompson JF, Cochran AJ, Mozzillo N, Elashoff R, et al. 2006. Sentinel-node biopsy or nodal observation in melanoma. N Engl J Med 355:1307-17

Morton DL, Wen DR, Wong JH, Economou JS, Cagle LA, et al. 1992. Technical details of intraoperative lymphatic mapping for early stage melanoma. Archives of Surgery 127:392-9

Morvillo V, Luthy IA, Bravo AI, Capurro MI, Portela P, et al. 2002. Androgen receptors in human melanoma cell lines IIB-MEL-LES and IIB-MEL-IAN and in human melanoma metastases. Melanoma Res 12:529-38

Mosca PJ, Teicher E, Nair SP, Pockaj BA. 2008. Can surgeons improve survival in stage IV melanoma? Journal of Surgical Oncology 97:462-8

National Cancer Institute. 2011. Cancer Topics: Melanoma. http://www.cancer.gov/ cancertopics/types/melanoma

Neifeld JP, Lippman ME. 1980. Steroid hormone receptors and melanoma. J Invest Dermatol 74:379-81

Newman MD, Lertsburapa T, Mirzabeigi M, Mafee M, Guitart J, Gerami P. 2009. Fluorescence in situ hybridization as a tool for microstaging in malignant melanoma. Mod Pathol 22:989-95

O'Brien CJ, Uren RF, Thompson JF, Howman-Giles RB, Petersen-Schaefer K, et al. 1995. Prediction of potential metastatic sites in cutaneous head and neck melanoma using lymphoscintigraphy. American Journal of Surgery 170:461-6

Ollila DW, Essner R, Wanek LA, Morton DL. 1996. Surgical resection for melanoma metastatic to the gastrointestinal tract. Archives of Surgery 131:975-9; 9-80

Ollila DW, Hsueh EC, Stern SL, Morton DL. 1999. Metastasectomy for recurrent stage IV melanoma. Journal of Surgical Oncology 71:209-13

Ollila DW, Stern SL, Morton DL. 1998. Tumor doubling time: a selection factor for pulmonary resection of metastatic melanoma. Journal of Surgical Oncology 69:206-11 
Padussis JC, Steerman SN, Tyler DS, Mosca PJ. 2008. Pharmacokinetics \& drug resistance of melphalan in regional chemotherapy: ILP versus ILI. International Journal of Hyperthermia 24:239-49

Paek SC, Griffith KA, Johnson TM, Sondak VK, Wong SL, et al. 2007. The impact of factors beyond Breslow depth on predicting sentinel lymph node positivity in melanoma. Cancer 109:100-8

Pages C, Robert C, Thomas L, Maubec E, Sassolas B, et al. 2010. Management and outcome of metastatic melanoma during pregnancy. British Journal of Dermatology 162:274-81

Panagiotou I, Brountzos EN, Bafaloukos D, Stoupis C, Brestas P, Kelekis DA. 2002. Malignant melanoma metastatic to the gastrointestinal tract. Melanoma Res 12:16973

Pappo AS. 2003. Melanoma in children and adolescents. Eur J Cancer 39:2651-61

Patel SG, Coit DG, Shaha AR, Brady MS, Boyle JO, et al. 2002. Sentinel lymph node biopsy for cutaneous head and neck melanomas. Arch Otolaryngol Head Neck Surg 128:28591

Perrott RE, Glass LF, Reintgen DS, Fenske NA. 2003. Reassessing the role of lymphatic mapping and sentinel lymphadenectomy in the management of cutaneous malignant melanoma. J Am Acad Dermatol 49:567-88; quiz 89-92

Petersen RP, Hanish SI, Haney JC, Miller CC, 3rd, Burfeind WR, Jr., et al. 2007. Improved survival with pulmonary metastasectomy: an analysis of 1720 patients with pulmonary metastatic melanoma. Journal of Thoracic \& Cardiovascular Surgery 133:104-10

Pfahlberg A, Hassan K, Wille L, Lausen B, Gefeller O. 1997. Systematic review of casecontrol studies: oral contraceptives show no effect on melanoma risk. Public Health Rev 25:309-15

Phan GQ, Messina JL, Sondak VK, Zager JS. 2009. Sentinel lymph node biopsy for melanoma: indications and rationale. Cancer Control 16:234-9

Pirker C, Holzmann K, Spiegl-Kreinecker S, Elbling L, Thallinger C, et al. 2003. Chromosomal imbalances in primary and metastatic melanomas: overrepresentation of essential telomerase genes. Melanoma Res 13:483-92

Pouryazdanparast P, Newman M, Mafee M, Haghighat Z, Guitart J, Gerami P. 2009. Distinguishing epithelioid blue nevus from blue nevus-like cutaneous melanoma metastasis using fluorescence in situ hybridization. Am J Surg Pathol 33:1396-400

Powell JW, Chung CT, Shah HR, Canute GW, Hodge CJ, et al. 2008. Gamma Knife surgery in the management of radioresistant brain metastases in high-risk patients with melanoma, renal cell carcinoma, and sarcoma. Journal of Neurosurgery 109 Suppl:122-8

Prosdocimo T, Smith M, Polack EP. 2002. The diagnosis and treatment of childhood melanoma. WV Med J 98:149-51

Ranieri JM, Wagner JD, Azuaje R, Davidson D, Wenck S, et al. 2002. Prognostic importance of lymph node tumor burden in melanoma patients staged by sentinel node biopsy. Annals of Surgical Oncology 9:975-81

Rao BN, Hayes FA, Pratt CB, Fleming ID, Kumar AP, et al. 1990. Malignant melanoma in children: its management and prognosis. Journal of Pediatric Surgery 25:198-203 
Rasgon BM. 2001. Use of low-dose technetium Tc 99m sulfur colloid to locate sentinel lymph nodes in melanoma of the head and neck: preliminary study. Laryngoscope 111:136672

Ridha H, Ahmed S, Theaker JM, Horlock N. 2007. Malignant melanoma and deep penetrating naevus--difficulties in diagnosis in children. Journal of Plastic, Reconstructive \& Aesthetic Surgery: JPRAS 60:1252-5

Roarke MC, Ram P, Nguyen BD. 2007. Utility of SPECT/CT in preoperative planning for sentinel lymph node biopsy in melanoma and head/neck carcinoma: three illustrative cases. Clinical Nuclear Medicine 32:464-5

Roaten JB, Pearlman N, Gonzalez R, Gonzalez R, McCarter MD. 2005. Identifying risk factors for complications following sentinel lymph node biopsy for melanoma. Archives of Surgery 140:85-9

Rose DM, Essner R, Hughes TM, Tang PC, Bilchik A, et al. 2001. Surgical resection for metastatic melanoma to the liver: the John Wayne Cancer Institute and Sydney Melanoma Unit experience. Archives of Surgery 136:950-5

Ross MI, Gershenwald JE. 2008. How should we view the results of the Multicenter Selective Lymphadenectomy Trial-1 (MSLT-1)? Ann Surg Oncol 15:670-3

Rossi CR, Pasquali S, Mocellin S, Vecchiato A, Campana LG, et al. 2010. Long-term results of melphalan-based isolated limb perfusion with or without low-dose TNF for intransit melanoma metastases. Annals of Surgical Oncology 17:3000-7

Roth ME, Grant-Kels JM, Kuhn MK, Greenberg RD, Hurwitz S. 1990. Melanoma in children. J Am Acad Dermatol 22:265-74

Rousseau C, Classe JM, Campion L, Curtet C, Dravet F, et al. 2005. The impact of nonvisualization of sentinel nodes on lymphoscintigraphy in breast cancer. Annals of Surgical Oncology 12:533-8

Sabel MS, Griffith KA, Arora A, Shargorodsky J, Blazer DG, 3rd, et al. 2007. Inguinal node dissection for melanoma in the era of sentinel lymph node biopsy. Surgery 141:72835

Saenz NC, Saenz-Badillos J, Busam K, LaQuaglia MP, Corbally M, Brady MS. 1999. Childhood melanoma survival. Cancer 85:750-4

Samlowski WE, Watson GA, Wang M, Rao G, Klimo P, Jr., et al. 2007. Multimodality treatment of melanoma brain metastases incorporating stereotactic radiosurgery (SRS). Cancer 109:1855-62

Sanki A, Kam PCA, Thompson JF. 2007. Long-term results of hyperthermic, isolated limb perfusion for melanoma: a reflection of tumor biology. Annals of Surgery 245:591-6

Sarnaik AA, Puleo CA, Zager JS, Sondak VK. 2009. Limiting the morbidity of inguinal lymphadenectomy for metastatic melanoma. Cancer Control 16:240-7

Schmid-Wendtner MH, Berking C, Baumert J, Schmidt M, Sander CA, et al. 2002. Cutaneous melanoma in childhood and adolescence: an analysis of 36 patients. Journal of the American Academy of Dermatology 46:874-9

Schuchter LM, Green R, Fraker D. 2000. Primary and metastatic diseases in malignant melanoma of the gastrointestinal tract. Curr Opin Oncol 12:181-5

Schwartz JL, Mozurkewich EL, Johnson TM. 2003. Current management of patients with melanoma who are pregnant, want to get pregnant, or do not want to get pregnant. Cancer 97:2130-3 
Scolyer RA, Murali R, McCarthy SW, Thompson JF. 2010. Histologically ambiguous ("borderline") primary cutaneous melanocytic tumors: approaches to patient management including the roles of molecular testing and sentinel lymph node biopsy. Arch Pathol Lab Med 134:1770-7

Scolyer RA, Thompson JF, Stretch JR, Sharma R, McCarthy SW. 2004. Pathology of melanocytic lesions: new, controversial, and clinically important issues. J Surg Oncol 86:200-11

Sim FH, Taylor WF, Pritchard DJ, Soule EH. 1986. Lymphadenectomy in the management of stage I malignant melanoma: a prospective randomized study. Mayo Clinic Proceedings 61:697-705

Socrier Y, Lauwers-Cances V, Lamant L, Garrido I, Lauwers F, et al. 2010. Histological regression in primary melanoma: not a predictor of sentinel lymph node metastasis in a cohort of 397 patients. British Journal of Dermatology 162:830-4

Sondak VK, Taylor JMG, Sabel MS, Wang Y, Lowe L, et al. 2004. Mitotic rate and younger age are predictors of sentinel lymph node positivity: lessons learned from the generation of a probabilistic model. Annals of Surgical Oncology 11:247-58

Soni M, Saha S, Korant A, Fritz P, Chakravarty B, et al. 2009. A prospective trial comparing $1 \%$ lymphazurin vs $1 \%$ methylene blue in sentinel lymph node mapping of gastrointestinal tumors. Annals of Surgical Oncology 16:2224-30

Stark M, Hayward N. 2007. Genome-wide loss of heterozygosity and copy number analysis in melanoma using high-density single-nucleotide polymorphism arrays. Cancer Res 67:2632-42

Storm FK, Sparks FC, Morton DL. 1979. Treatment for melanoma of the lower extremity with intralesional injection of bacille Calmette Guerin and hyperthermic perfusion. Surgery, Gynecology \& Obstetrics 149:17-21

Strouse JJ, Fears TR, Tucker MA, Wayne AS. 2005. Pediatric melanoma: risk factor and survival analysis of the surveillance, epidemiology and end results database. Journal of Clinical Oncology 23:4735-41

Sutherland AD, Faragher IG, Frizelle FA. 2009. Intradermal injection of methylene blue for the treatment of refractory pruritus ani. Colorectal Disease 11:282-7

Tannous ZS, Mihm MC, Jr., Sober AJ, Duncan LM. 2005a. Congenital melanocytic nevi: clinical and histopathologic features, risk of melanoma, and clinical management. Journal of the American Academy of Dermatology 52:197-203

Tannous ZS, Mihm MC, Jr., Sober AJ, Duncan LM. 2005b. Congenital melanocytic nevi: clinical and histopathologic features, risk of melanoma, and clinical management. J Am Acad Dermatol 52:197-203

Tarhini AA, Agarwala SS. 2004. Management of brain metastases in patients with melanoma. Curr Opin Oncol 16:161-6

Teltzrow T, Osinga J, Schwipper V. 2007. Reliability of sentinel lymph-node extirpation as a diagnostic method for malignant melanoma of the head and neck region. International Journal of Oral \& Maxillofacial Surgery 36:481-7

Testori A, Rutkowski P, Marsden J, Bastholt L, Chiarion-Sileni V, et al. 2009. Surgery and radiotherapy in the treatment of cutaneous melanoma. Ann Oncol 20 Suppl 6:vi22-9

Topar G, Zelger B. 2007. Assessment of value of the sentinel lymph node biopsy in melanoma in children and adolescents and applicability of subcutaneous infusion anesthesia. Journal of Pediatric Surgery 42:1716-20 
Tyler D, Ross M. 2008. The role that regional therapy plays in the current day management of cancer that is confined to the extremities. Introduction. International Journal of Hyperthermia 24:183

van Akkooi AC, Bouwhuis MG, de Wilt JH, Kliffen M, Schmitz PI, Eggermont AM. 2007. Multivariable analysis comparing outcome after sentinel node biopsy or therapeutic lymph node dissection in patients with melanoma. Br J Surg 94:1293-9

van Akkooi AC, de Wilt JH, Verhoef C, Schmitz PI, van Geel AN, et al. 2006. Clinical relevance of melanoma micrometastases $(<0.1 \mathrm{~mm})$ in sentinel nodes: are these nodes to be considered negative? Ann Oncol 17:1578-85

van Akkooi AC, Voit CA, Verhoef C, Eggermont AM. New developments in sentinel node staging in melanoma: controversies and alternatives. Curr Opin Oncol 22:169-77

van Akkooi ACJ, Spatz A, Eggermont AMM, Mihm M, Cook MG. 2009. Expert opinion in melanoma: the sentinel node; EORTC Melanoma Group recommendations on practical methodology of the measurement of the microanatomic location of metastases and metastatic tumour burden. European Journal of Cancer 45:2736-42

van der Ploeg APT, van Akkooi ACJ, Schmitz PIM, Koljenovic S, Verhoef C, Eggermont AMM. 2010. EORTC Melanoma Group sentinel node protocol identifies high rate of submicrometastases according to Rotterdam Criteria. European Journal of Cancer 46:2414-21

van der Ploeg IMC, Valdes Olmos RA, Kroon BBR, Nieweg OE. 2008. Tumor-positive sentinel node biopsy of the groin in clinically node-negative melanoma patients: superficial or superficial and deep lymph node dissection? Annals of Surgical Oncology 15:1485-91

van der Ploeg IMC, Valdes Olmos RA, Kroon BBR, Wouters MWJM, van den Brekel MWM, et al. 2009. The yield of SPECT/CT for anatomical lymphatic mapping in patients with melanoma. Annals of Surgical Oncology 16:1537-42

Vermeeren L, van der Ploeg IMC, Olmos RAV, Meinhardt W, Klop WMC, et al. 2010. SPECT/CT for preoperative sentinel node localization. Journal of Surgical Oncology 101:184-90

Veronesi U, Adamus J, Bandiera DC, Brennhovd IO, Caceres E, et al. 1977. Inefficacy of immediate node dissection in stage 1 melanoma of the limbs. New England Journal of Medicine 297:627-30

Veronesi U, Cascinelli N, Adamus J, Balch C, Bandiera D, et al. 1988. Thin stage I primary cutaneous malignant melanoma. Comparison of excision with margins of 1 or $3 \mathrm{~cm}$. N Engl J Med 318:1159-62

Wagner JD, Corbett L, Park HM, Davidson D, Coleman JJ, et al. 2000. Sentinel lymph node biopsy for melanoma: experience with 234 consecutive procedures. Plastic $\mathcal{E}$ Reconstructive Surgery 105:1956-66

Wells KE, Rapaport DP, Cruse CW, Payne W, Albertini J, et al. 1997. Sentinel lymph node biopsy in melanoma of the head and neck. Plast Reconstr Surg 100:591-4

Wilke LG, McCall LM, Posther KE, Whitworth PW, Reintgen DS, et al. 2006. Surgical complications associated with sentinel lymph node biopsy: results from a prospective international cooperative group trial. Annals of Surgical Oncology $13: 491-500$ 
Wong SL, Brady MS, Busam KJ, Coit DG. 2006a. Results of sentinel lymph node biopsy in patients with thin melanoma. Annals of Surgical Oncology 13:302-9

Wong SL, Brady MS, Busam KJ, Coit DG. 2006b. Results of sentinel lymph node biopsy in patients with thin melanoma. Ann Surg Oncol 13:302-9

Wood TF, DiFronzo LA, Rose DM, Haigh PI, Stern SL, et al. 2001. Does complete resection of melanoma metastatic to solid intra-abdominal organs improve survival? Annals of Surgical Oncology 8:658-62

Wrightson WR, Wong SL, Edwards MJ, Chao C, Reintgen DS, et al. 2003. Complications associated with sentinel lymph node biopsy for melanoma. Annals of Surgical Oncology 10:676-80

Young SE, Martinez SR, Essner R. 2006. The role of surgery in treatment of stage IV melanoma. Journal of Surgical Oncology 94:344-51 


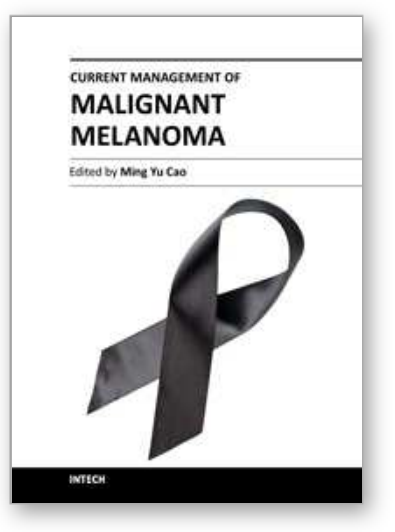

\author{
Current Management of Malignant Melanoma \\ Edited by Dr. Ming Yu Cao
}

ISBN 978-953-307-264-7

Hard cover, 274 pages

Publisher InTech

Published online 22, September, 2011

Published in print edition September, 2011

Management of melanoma is challenging, especially for the late stage of the disease. Development of new therapies and optimizing current treatments are being pursued in attempt to further improve the survival rate. The book provides up-to-date knowledge and experience in early diagnosis, prevention and treatment of melanoma as well as current ongoing clinical studies on melanoma. The book also provides the most recent perspectives of research on the molecular basis of melanoma, such as melanoma associated genes and a possible link between stress and melanoma.

\title{
How to reference
}

In order to correctly reference this scholarly work, feel free to copy and paste the following:

Asvin M. Ganapathi, Douglas S. Tyler and Paul J. Mosca (2011). Challenging Problems in the Surgical Management of Melanoma, Current Management of Malignant Melanoma, Dr. Ming Yu Cao (Ed.), ISBN: 978953-307-264-7, InTech, Available from: http://www.intechopen.com/books/current-management-of-malignantmelanoma/challenging-problems-in-the-surgical-management-of-melanoma

\section{INTECH}

open science / open minds

\section{InTech Europe}

University Campus STeP Ri

Slavka Krautzeka 83/A

51000 Rijeka, Croatia

Phone: +385 (51) 770447

Fax: +385 (51) 686166

www.intechopen.com

\section{InTech China}

Unit 405, Office Block, Hotel Equatorial Shanghai

No.65, Yan An Road (West), Shanghai, 200040, China

中国上海市延安西路65号上海国际贵都大饭店办公楼405单元

Phone: +86-21-62489820

Fax: +86-21-62489821 
(C) 2011 The Author(s). Licensee IntechOpen. This chapter is distributed under the terms of the Creative Commons Attribution-NonCommercialShareAlike-3.0 License, which permits use, distribution and reproduction for non-commercial purposes, provided the original is properly cited and derivative works building on this content are distributed under the same license. 